\title{
The FAMOUS TRIAGE trial - pre-hospital chest pain research challenging the paradigm
}

Premature diagnostic closure is a well-recognized contributor to medical error and missed diagnosis. This is particularly so for patients with chest pain, to the extent where national guidelines specify that assessment for rare but life threatening diagnoses such as aortic dissection and pulmonary embolism (PE) should form part of the clinical evaluation of chest pain patients - before jumping to a rule out acute coronary syndrome (ACS) pathway approach.[1] It has also been a factor in several coronial investigations.[2]

Recently I have followed with interest the FAMOUS TRIAGE trial being conducted in the Netherlands.[3] It aims to risk stratify chest pain patients attended by ambulance to risk groups based on ECG, a risk stratification tool (not yet finalised but probably the HEART score) and a single high sensitivity troponin point-of-care assay. The hoped-for outcome is the ability to stratify patients without ST elevation on ECG into a high risk group with established non-ST elevation myocardial infarction for transfer to a PCl hospital, a moderate risk group who could be evaluated at the nearest hospital and a group at low risk of major adverse cardiac events (MACE) who could be further evaluated at home or in primary care. Preliminary results suggest that of the order of $36 \%$ of patients may meet low risk criteria and that none had a MACE $(0 \%, 95 \% 0-1 \%)$.[4] This data needs to be interpreted with caution as HEART scores were calculated retrospectively by cardiology residents and not by the ambulance clinicians. Also I cannot find any evidence reporting agreement between HEART scores calculated by nurses or paramedics with those calculated by medical officers.

A pre-hospital process such as this, if safe, has the potential to improve ambulance and emergency department (ED) efficiency and allay patient concern quickly for low risk patients.

This is the author manuscript accepted for publication and has undergone full peer review but has not been through the copyediting, typesetting, pagination and proofreading process, which may lead to differences between this version and the Version of Record. Please cite this article as doi: $10.1111 / 1742-6723.13116$

This article is protected by copyright. All rights reserved. 
Although it is true that most chest pain patients assessed in ED are discharged after evaluation with a benign diagnosis and only about $10 \%$ rule in for ACS, a very small proportion have another life-threatening condition such as aortic dissection or PE. These are rare $-\mathrm{PE}$ about $1 \%$ of chest pain presentations and aortic dissection about $0.03 \%$. The inclusion criteria of the trial specify that 'suspicion of aortic dissection or pulmonary embolism' is an exclusion criterion. That assessment is made by registered ambulance nurses who have undergone special postgraduate training in critical care and advanced life support but the processes for that assessment are unclear.

This innovative process requires validation of its preliminary findings and implementation with evaluation but raises some interesting questions, particularly as the emergency care systems are different between the Netherlands and Australasia. Access to ED in the Netherlands is largely restricted to patients arriving by ambulance or referred by GPs and ambulance clinicians have quite different training models. Could this model be safely transferable to other ambulance services whose clinicians may have different training? What is the risk of diagnostic error/ premature closure - both at the ambulance level and at the primary care level for those patients re-directed there? Will low risk patients actually follow up with a primary care assessment rather than assuming that the ambulance assessment is sufficient and what, if any, are the consequences of this? How is timely access to primary care assessment achieved? Are Australian GPs confident that they have the skills and access to resources to safely complete an evaluation, especially if further tests are required? What proportion of low risk patients would be sent by GPs to ED for further evaluation in ED resulting in patient inconvenience, potential confusion and delay? I don't have the answers but believe the debate/ discussion should begin. 
1. Chew DP, Scott IA, Cullen L, French JK, Briffa TG, Tideman PA et al. National Heart Foundation of Australia \& Cardiac Society of Australia and New Zealand: Australian Clinical Guidelines for the Management of Acute Coronary Syndromes 2016. Heart Lung Circ. 2016 25:895-951

2. Jelinek GA. Bugeja LC, Spanos PA, Neate SL, Bergman RL, Ranson DL. Collaboration between the coroner and emergency physicians: efforts to improve outcomes from aortic dissection. Med J Aust 2014;201:607-9

3. Ishak M, Ali D, Fokkert MJ, Slingerland RJ, Dikkeschei B, Tolsma RT et al. Fast assessment and management of chest pain without ST-elevation in the pre-hospital gateway: Rationale and design. Eur Heart J: Acute Cardiovasc Care 2015; 4:129_ 136.

4. Ishak M, Ali D, Fokkert MJ, Slingerland RJ, Tolsma RT, Badings E et al. Fast assessment and management of chest pain patients without ST-elevation in the prehospital gateway (FamouS Triage): ruling out a myocardial infarction at home with the modified HEART score. Eur Heart J: Acute Cardiovasc Care 2018; 7:102-110.

This article is protected by copyright. All rights reserved. 


\section{University Library}

\section{- M M N E R VA A gateway to Melbourne's research publications}

Minerva Access is the Institutional Repository of The University of Melbourne

Author/s:

Kelly, A-M

Title:

The FAMOUS TRIAGE trial: Pre-hospital chest pain research challenging the paradigm

Date:

2018-08-01

Citation:

Kelly, A. -M. (2018). The FAMOUS TRIAGE trial: Pre-hospital chest pain research

challenging the paradigm. EMERGENCY MEDICINE AUSTRALASIA, 30 (4), pp.594-594. https://doi.org/10.1111/1742-6723.13116.

Persistent Link:

http://hdl.handle.net/11343/284038 